\title{
Chapter 1 \\ The National Centre for Cultural Competence: Transformative Journeys
}

\author{
Jack Frawley, Tran Nguyen, and Emma Sarian
}

\begin{abstract}
The University of Sydney's National Centre for Cultural Competence (NCCC) hosts professional development programmes for professional staff and academics to be able to actively, ethically, respectfully and successfully engage in intercultural settings, including the ability to engage meaningfully with cultures, histories and contemporary issues of Aboriginal and Torres Strait Islander communities. In addition, several resources and online modules have been developed for students. These programmes and resources support staff and students from across the University to develop their capability, capacity and resilience for cultural competence and help deepen connections between leadership, cultural competence and Aboriginal and Torres Strait Islander contexts. It is suggested in this chapter that transformative learning is best suited to cultural competence education.
\end{abstract}

Keywords Cultural competence $\cdot$ Transformative learning $\cdot$ Cultural change

\section{Introduction}

In the planning phase for establishment of the National Centre for Cultural Competence (NCCC) it was foreseen that it would be the first knowledge centre in Australia specifically established to foster scholarship and research in and translation of cultural competence. Over the six years of the funding period, the NCCC would evolve into a nationally and internationally recognised leader in the development of cultural competence knowledge and practice. The programmes and activities of the NCCC would align with and be informed by the University of Sydney's Wingara Mura-Bunga Barrabugu Aboriginal and Torres Strait Islander Integrated Strategy (University of Sydney, 2012). The Wingara Mura strategy sets out a whole-of-university approach to the development and integration of Indigenous cultures, pedagogies and epistemologies within the University, including the establishment of cultural competence as a graduate quality.

\footnotetext{
J. Frawley $(\varangle) \cdot$ T. Nguyen $\cdot$ E. Sarian

National Centre for Cultural Competence, The University of Sydney, Sydney, NSW, Australia e-mail: jack.frawley@ sydney.edu.au 
The strategic vision of the NCCC was not only that it would inform, shape and promote cultural competence narratives, action and capability to the university community at the first instance, but also widen its reach both nationally and internationally. While initially focused on, and built on an Australian Indigenous foundation, the NCCC would increase its relevance to other diverse communities, especially within the University of Sydney context, and contribute to the development of the university as culturally competent and in doing so contribute to the professional development of its staff and the academic success of its students.

Cultural competence has been described as an evasive concept to define, and that the emphasis instead should be on viewing the concept as a transformative journey. The interdisciplinary field is also scattered with other interrelated concepts such as cultural humility, cultural responsiveness, cultural plasticity, intercultural competence and multicultural competence. Even so, it is the definition of cultural competence by Cross et al. (1989) that has the most traction. Cross et al. (1989, p. iv) define cultural competence as 'a set of congruent behaviours, attitudes, and policies that come together in a system, agency, or among professionals and enables that system, agency, or those professionals to work effectively in cross-cultural situations'. Cross et al. (1989) emphasise that a culturally competent system should value diversity and have the capacity for individuals and systems to be able to undertake cultural self-assessment. The University of Sydney's 2016-2020 strategy views cultural competence as a key quality in addressing excellence as well as a discrete graduate quality, that is embedded as a learning outcome in every degree. The NCCC, while still in its early stages, has been instrumental in supporting a whole-of-university approach to the strategic plan, policies and programmes that assist academic and professional staff and students to navigate their journey through a cultural competence landscape, and these transformative journeys including perspectives on practice and projects are described in this volume.

\section{The Cultural Competence and Higher Education Interface: The National Centre for Cultural Competence Foundational Work}

Cultural competence has increasingly been viewed as a necessary response to growing diversity in higher education in Australia and other countries. Specifically, cultural competence is considered as one of the important tools that higher education institutions can use to respond to globalisation (Palmer \& Carter, 2014). It is also a channel through which the academy expresses its voice for social justice (Sherwood \& Russell-Mundine, 2017; Kruse, Rakha, \& Calderone, 2018). In parallel with developing students' cultural competence (Goodman, 2013), there have also been similar calls to programmes and initiatives promoting cultural competence for staff. Some key aims of this novel professional development approach are to enable 
staff in higher education to adapt well to the diversifying workforce, to work effectively with diverse populations and being responsible for teaching in such a way that demonstrates a commitment to the principle of respect for all (Brown, 2004).

Cultural change in higher education, as Kruse and colleagues (2018) have acknowledged, is neither easy nor certain. The authors observe that it is not that higher education institutions have not strived to enable staff and students to become culturally competent, but that they have performed this in uncoordinated and unsystematic ways. Sherwood and Russell-Mundine (2017) when discussing the NCCC's effort of promoting cultural competence within the University of Sydney context also recognise that one of the greatest challenges for the Centre is to be strategic about where it should focus its efforts. Furthermore, it is important for each higher education institution to determine the desired outcomes of cultural competence that it aims to achieve, either cognitive, attributional, experiential and/or behavioural at both individual and institutional level, the latter with a focus on policy and practice (Bezrukova, Jehn, \& Spell, 2012).

There have also been significant barriers and challenges to the development of cultural competence at the higher education interface. For example, people with longheld beliefs may resist a strong behavioural change-oriented programme focused on understanding specific areas of difference (Bezrukova et al., 2012). Staff may also raise significant questions about what cultural competence actually means, why it is important, what intercultural skills and knowledge should students acquire in a globalised world and what roles academics and institutions play in mentoring students in developing cultural competence (Pinto, 2018). Additionally, the dominant neo-liberalist environment in higher education today can hinder the development of a cultural competence agenda when this project may have to compete with other agendas and goals (Kruse et al., 2018).

Reviewing the current literature, Kruse and colleagues (2018) identify six conditions that they contend are necessary to support strong cultural competence agendas in higher education. These conditions include:

1. Time to meet, learn and process new learning — with the focus on allowing staff to have the opportunity to interact and work with people, as well as on staff's knowledge development;

2. Time to monitor, evaluate and refine processes and practices across the campus - this will enable higher education institutions to evaluate their progress in achieving the desired outcomes of cultural competence;

3. Communication structures that support the work of cultural competence-those structures can include different forms, for example, both face-to-face or online communication that foster the exchange of ideas, discussion and networking within and across the institution;

4. A climate of trust and openness to improvement and learning-with trust expressed in various forms such as institution members' willingness to participate in events and dialogue; 
5. Supportive leadership from higher education institutions such as presidents, provosts, deans or department chairs - such leadership is critical to determine whether or not cultural competence agendas are to be successful;

6. Access to expertise designed to support individual and organisational learning, as the attainment of cultural competence requires faculty and staff to have access to expertise in content and practice.

At the University of Sydney, the establishment of the NCCC is viewed as a critical starting point to develop a whole-of-institution agenda of cultural competence on campus. The NCCC's work over the past five years since its inception illustrates the Centre's efforts to lay important foundations for cultural change to take place at the University. With the ultimate aim of instigating cultural competence as a transformational change and social justice education agent (Sherwood \& RussellMundine, 2017), the NCCC has increasingly expanded its research and teaching work both within and beyond the University campus. The NCCC has developed foundational resources to support and encourage University staff to take up cultural competence philosophy and pedagogy in their curriculum, teaching and research.

One of the NCCC's key activities is delivering workshops that focus on foundational elements of cultural competence such as developing critical self-reflection capabilities, understanding socialisation and worldview, or understanding one's cultural identities (see Sherwood \& Russell-Mundine, 2017; McHugh-Cole, Simons and Russell this volume). Additionally, through its Culturally Competent Leadership Program (CCLP) (see Pecci, Frawley and Nguyen this volume), the NCCC has created a valuable and exciting opportunity for University staff to have time to meet, network and exchange ideas about promoting cultural competence on campus and beyond.

The NCCC's other significant work includes the development of online learning modules which have facilitated greater access for both University staff and students to gain better knowledge about cultural competence (National Centre for Cultural Competence, 2019). In 2018, the NCCC hosted the international conference on Cultural Competence and the Higher Education Sector: Dilemmas, Policies and Practice (The University of Sydney, 2018). The conference created an important platform for academics and policy-makers to network, share information and create a national dialogue on the topic of cultural competence. The conference also provided an opportunity to explore different and innovative approaches and strategies that incorporate Indigenous knowledges and practices into the development and implementation of cultural competence in the higher education sector. The NCCC's work so far has thus contributed to producing a climate of trust and openness at the University that is essential to foster cultural competence, as well as building leadership capacity in the field. In recognition of the need to move beyond knowledge and skill acquisition, most cultural competence education programmes like those offered by the NCCC employ some form of transformative learning. 


\section{Transformative Practice and Perspectives}

One of the overarching themes of the chapters in this book is the recognition that the pedagogy of cultural competence cannot be reduced to simple frameworks of knowledge or skill transfer. It is for this reason that many cultural competence educators have adopted, either implicitly or explicitly, the pedagogical framework of transformative learning. Introduced by Mezirow in 1978, transformative learning suggests that adult learning is a distinct process from childhood learning, and that traditional forms of instructivist pedagogy, in which information is passively delivered and consumed, is not a suitable or effective model for adult learners (Kitchenham, 2008).

Instead, Mezirow proposes that learning for adults should be understood in terms of 'perspective transformation', in which existing meaning-making frameworks are challenged by new information. Importantly, according to Mezirow, experiencing such a challenge is not enough on its own but requires critical self-reflection on the part of the learner, both to become aware of their existing frame and then to understand how new information challenges this frame. Thus, for Mezirow, perspective transformation is 'the emancipatory process of becoming critically aware of how and why the structure of psycho-cultural assumptions has come to constrain the way we see ourselves and our relationships, reconstituting this structure to permit a more inclusive and discriminating integration of experience and acting upon these new understandings' (Mezirow, 1981, p. 6).

It is for this reason that much of the literature on cultural competence has turned to the framework of transformative learning in order to think through pedagogical best practice, since it works from a conceptualisation of learning as self-directed and self-reflexive. A number of cultural competence educators point to the transformative learning framework as particularly suitable for developing cultural competence because it 'invokes having openness to the views and experiences of others, willingness to consider different beliefs and perspectives, listening with empathy, suspending hasty judgement and understanding the experiences that have shaped the views we hold' (Jackson, Power, Sherwood, \& Geia, 2013, p. 107; see also Lewis, Lewis, \& Williams, 2014; Taylor, 1994). While the transformative learning framework is not always explicitly acknowledged, its influence on the pedagogical practices explored within this book is clear.

In particular, four fundamental components of transformative learning have been identified by Taylor (2000) as integral to the development of cultural competence. These components are:

1. Group setting

2. Shared experiential learning

3. Value-laden content

4. Affective learning.

First, there is general consensus that cultural competence is best developed in a group setting, which reflects the transformative learning principle that learning 
requires listening to others and self-reflecting in order to evaluate what is being communicated (Mezirow, 2003). By facilitating cultural competence development within a group, cultural competence skills can immediately be engaged, as learners are exposed to worldviews that differ from their own within an environment that facilitates self-reflection on these differences. For instance, in Chap. 2, Cole et al. explore a model of cultural competence development that includes both online resources as well as face-to-face workshops, acknowledging the need for more traditional forms of knowledge transfer as well as facilitated group interaction.

Supplementary to this is a need for shared experiential learning, which can be defined as 'the process whereby knowledge is created through the transformation of experience' (Kolb, 2014, p. 38). This emphasis on experiential learning underscores how both transformative learning and cultural competence frameworks conceptualise meaning-making not exclusively as an intellectual process. In these terms, meaningmaking frameworks are challenged by reflecting on experience, and this includes both prior lived experience as well as experiential learning activities. In Chap. 5, Forsyth et al. detail what this experiential self-reflection looks like in the process of integrating cultural competence within dentistry education, demonstrating that practising cultural competence is essential not only for students but also the staff who seek to include it within their curricula.

The third component for cultural competence development is value-laden content; that is, learning content must explicitly identify and encourage reflection on personal values, and how these align with the values of critical cultural competence education. In particular, the relationship between cultural competence and issues of inequality, power and social justice must be made clear in order to more explicitly challenge learners' worldviews. As Rivera (2010) suggest:

the inconsistency between universally-espoused values of fairness and respect, on the one hand, and, on the other, prejudice and discrimination... can be explored in the classroom, with the expectation of dissonance and subsequent movement toward at least attempts at a resolution of value conflicts (2010, pp. 17-18; see also McGregor, 1993).

Both Daniels-Mayes and Gongora et al. raise these issues on embedding cultural competence within their curricula in Chaps. 4 and 6, respectively, and both of their programmes include student awareness of the social justice element in cultural competence as a key outcome.

Finally, the affective component of cultural competence learning must be engaged, in recognition of the relationship between emotional responses and how they invoke or impede self-reflection. In these terms, perspective transformation is not simply an intellectual process but also an emotional one, an element that was missing from Mezirow's initial model of transformative learning and which he later corrected (2000). Instead, as Taylor suggests, 'it is the learners' emotions and feelings that not only provide the impetus for them to reflect critically, but often provide the gist on which to reflect deeply' (Taylor, 2000, p. 16). In Chap. 7, Phillips and Ly consider the emotional dimension of maths education and the trauma that is sometimes associated with it, and the need for creating culturally safe spaces for students to regain their confidence. 
Ultimately, as the chapters in this book demonstrate, it is this transformative aspect of cultural competence development that produces difficulties for integration into institutional systems such as the university. Questions around assessment, evaluation and metrics - foundational to the logics of contemporary university governance - are inevitably raised with the adoption of a transformative learning approach, and it is perhaps in this area that consistent evaluation of the University's current cultural competence policies and programmes is required. Nevertheless, the existing scholarship on critical cultural competence is clear that teaching cultural competence cannot and should not be reduced to a box-ticking exercise, and each of the experiences outlined in this book can be understood as responding to this tension in various ways.

\section{Conclusion}

The growing diversity in culture, knowledge, skills and capabilities that students bring to tertiary education requires appropriate pedagogical responses. Cultural competence education of both students and staff is viewed as an essential and appropriate tool in addressing diversity. Nevertheless, there is a corresponding need to move beyond knowledge and skills acquisition, to a more transformative experience underlined by learning that is self-directive and self-reflexive. Taylor's (2000) components of group setting, shared experiential learning, value-laden content and affective learning are viewed as being the key to developing cultural competence for both students and staff. At the University of Sydney, the NCCC to date has had a crucial and successful role in supporting staff and students to undertake their own transformative cultural competence journey.

\section{References}

Bezrukova, K., Jehn, K., \& Spell, C. (2012). Reviewing diversity training: Where we have been and where we should go. Academy of Management Learning and Education, 11(2), 207-227.

Brown, L. (2004). Diversity: The challenge for higher education. Race Ethnicity and Education, 7(1), 21-34.

Cross, T. L., Bazron, B. J., Dennis, K. W., \& Isaacs, M. R. (1989). Towards a culturally competent system of care: A monograph on effective services for minority children who are severely emotionally disturbed. Washington, DC: Child and Adolescent Service System Program Technical Assistance Center, Georgetown University Child Development Center.

Goodman, D. (2013). Cultural competency for social justice. Retrieved from https://acpacsje. wordpress.com/2013/02/05/cultural-competency-for-social-justice-by-diane-j-goodman-ed-d/.

Jackson, D., Power, T., Sherwood, J., \& Geia, L. (2013). Amazingly resilient Indigenous people! Using transformative learning to facilitate positive student engagement with sensitive material. Contemporary Nurse, 46, 105-112. https://doi.org/10.5172/conu.2013.46.1.105.

Kitchenham, A. (2008). The evolution of John Mezirow's transformative learning theory. Journal of Transformative Education, 6, 104-123. https://doi.org/10.1177/1541344608322678. 
Kolb, D. A. (2014). Experiential learning: Experience as the source of learning and development. FT Press.

Kruse, S. D., Rakha, S., \& Calderone, S. (2018). Developing cultural competency in higher education: an agenda for practice. Teaching in Higher Education, 23(6), 733-750.

Lewis, P. H., Lewis, A. N., \& Williams, F. D. (2014). Cultural competency in public administration programs. Cultural Competency for Public Administrators, 244.

McGregor, J. (1993). Effectiveness of role playing and anti-racist teaching in reducing student prejudice. The Journal of Educational Research, 86, 215-226. https://doi.org/10.1080/00220671. 1993.9941833.

Mezirow, J. (2003). Transformative learning as discourse. Journal of Transformative Education, 1, 58-63. https://doi.org/10.1177/1541344603252172.

Mezirow, J. (1981). A critical theory of adult learning and education. Adult Education, 32, 3-24. https://doi.org/10.1177/074171368103200101.

National Centre for Cultural Competence (2019). Learning Resources. Retrieved from https:// sydney.edu.au/nccc/training-and-resources/resources.html.

Palmer, J., \& Carter, J. (2014). Working in the border zone: developing cultural competence in higher education for a globalised world. Knowledge Cultures, 2(4), 22-44.

Pinto, S. (2018). Intercultural competence in higher education: academics' perspectives. On the Horizon, 26(2), 137-147.

Rivera, M. A. (2010). The ethics of pedagogical innovation in diversity and cultural competency education. The Innovation Journal, 15(2), 1-18

Sherwood, J., \& Russell-Mundine, G. (2017) How we do business: Setting the agenda for cultural competence at the University of Sydney. In J. Frawley, S. Larkin, \& J. A. Smith J. (Eds), Indigenous Pathways, Transitions and Participation in Higher Education. Singapore: Springer Open.

Taylor, E. (2000). Fostering Mezirow's transformative learning theory in the adult education classroom: A critical review. Canadian Journal for the Study of Adult Education, 14(2), 1-28.

Taylor, E. W. (1994). Intercultural competency: A transformative learning process. Adult Education Quarterly, 44, 154-174. https://doi.org/10.1177/074171369404400303.

The University of Sydney. (2018). What role does cultural competence have in higher education? Retrieved from https://sydney.edu.au/news-opinion/news/2018/03/26/what-role-doescultural-competence-have-in-higher-education-.html.

The University of Sydney. (2016). If you change nothing, nothing will change: 2016-2020 Strategic plan. Retrieved from https://www.sydney.edu.au/content/dam/intranet/documents/strategy-andplanning/strategic-plan-2016-20.pdf.

Open Access This chapter is licensed under the terms of the Creative Commons Attribution 4.0 International License (http://creativecommons.org/licenses/by/4.0/), which permits use, sharing, adaptation, distribution and reproduction in any medium or format, as long as you give appropriate credit to the original author(s) and the source, provide a link to the Creative Commons license and indicate if changes were made.

The images or other third party material in this chapter are included in the chapter's Creative Commons license, unless indicated otherwise in a credit line to the material. If material is not included in the chapter's Creative Commons license and your intended use is not permitted by statutory regulation or exceeds the permitted use, you will need to obtain permission directly from the copyright holder.

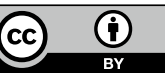

